\title{
Polioencefalomalacia experimental em bovinos induzida por toxicose por enxofre ${ }^{1}$
}

\begin{abstract}
Paulo H.J. Cunha ${ }^{2}$, Peres R. Badial ${ }^{3}$, Didier Q. Cagnini ${ }^{3}$, José P. Oliveira-Filho ${ }^{3}$, Lívia F. Moares ${ }^{3}$, Regina K. Takahira ${ }^{3}$, Renée L. Amorim ${ }^{3}$ e Alexandre S. Borges ${ }^{3}$

ABSTRACT.- Cunha P.H.J., Badial P.R., Cagnini D.Q., Oliveira Filho J.P., Moraes L.F., Takahira R.K., Amorim R.L. \& Borges A.S. 2011. [Experimental polioencephalomalacia in cattle induced by sulfur toxicosis.] Polioencefalomalacia experimental em bovinos induzida por toxicose por enxofre. Pesquisa Veterinária Brasileira 31(1):41-52. Departamento de Medicina Veterinária, Escola de Veterinária, Universidade Federal de Goiás, Rua 13 no.278, Apto 400, Plaza Residencial Sol de La Plaza, Setor Oeste, Goiânia, GO 74120-060, Brazil. E-mail: phcunhavet@yahoo.com.br

The aims of this study were to evaluate the clinical signs, the ruminal hydrogen sulfide concentration and the histological lesions induced by sulfur toxicosis in cattle. Ten crossbred calves were fed an experimental diet, four without sodium sulfate (G1) and six with (G2). The calves were submitted to clinical (rectal temperature, cardiac and respiratory rate and ruminal motricity) and laboratorial (hemogram, fibrinogen, total plasma protein, ruminal fluid $\mathrm{pH}$, ruminal hydrogen sulfide concentration, cerebrospinal fluid and histopathological) evaluations. Rectal temperature, cardiac rate, hemogram, fibrinogen, total plasma protein, ruminal fluid $\mathrm{pH}$ and cerebrospinal fluid values were within normal reference ranges in animals from both groups. Ruminal hypomotricity and increased respiratory rate and ruminal hydrogen sulfide concentration occurred in G2 animals. One out of six calves in G2 developed neurological signs and lesions of PEM. Two calves of each Group were euthanized. Microscopic lesions of PEM were observed in G2 animals. Histologically there were cortical neuronal necrosis and hemorrhagic lesions in basal nuclei, thalamus, midbrain, pons and medulla oblongata. The experimental model consisting of a diet with high carbohydrate and low in long fiber content with high sulfur concentrations $(0.52 \%)$ resulted in clinical and histological abnormalities and high ruminal hydrogen sulfide concentration consistent with sulpur toxicosis in cattle.
\end{abstract}

INDEX-TERMS: Cerebrocortical necrosis, sulfur, cattle, experimental model, ruminal hydrogen sulfide.

RESUMO.- O presente trabalho teve como objetivos avaliar os sinais clínicos, as concentrações do sulfeto de hidrogênio ruminal e as alterações anatomopatológicas associadas à intoxicação experimental por enxofre em bovinos. Foram utilizados dez bezerros mestiços leiteiros, sen-

\footnotetext{
${ }^{1}$ Recebido em 9 de março de 2010.

Aceito para publicação em 6 de setembro de 2010.

Parte da tese de Doutorado do primeiro autor. Financiado integralmente pela Fundação de Amparo à Pesquisa do Estado de São Paulo (2006/05836-6).

2 Depto Medicina Veterinária, Escola de Veterinária, Universidade Federal de Goiás (UFG). Endereço particular: Rua 13 no.278, Apto 400, Plaza Residencial Sol de La Plaza, Setor Oeste, Goiânia, GO 74120060, Brasil. *Autor para correspondência: phcunhavet@yahoo.com.br

${ }^{3}$ Departamento de Clínica Veterinária, Faculdade de Medicina Veterinária e Zootecnia, Universidade Estadual Paulista (Unesp), Campus de Botucatu, Distrito de Rubião Júnior s/n, Botucatu, SP 18618-000, Brasil.
}

do que quatro bovinos ingeriram ração sem sulfato de sódio (G1) e seis consumiram ração com sulfato de sódio (G2). Exames clínicos (temperatura retal, frequência cardíaca e respiratória e motricidade ruminal) e laboratoriais (hemograma, fibrinogênio, proteína plasmática, $\mathrm{pH}$ do fluido ruminal, concentração do sulfeto de hidrogênio ruminal, líquido cerebrospinal e histopatológico) foram realizados. A temperatura retal, frequência cardíaca, hemograma, fibrinogênio, proteína plasmática, $\mathrm{pH}$ do fluido ruminal e os valores do líquido cerebrospinal estavam dentro dos valores de referência para a espécie. Taquipnéia, hipomotricidade ruminal e elevados valores de sulfeto de hidrogênio ruminal foram observados nos bezerros do grupo G2. Um bezerro do grupo G2 apresentou sinais neurológicos e lesões histopatológicas de PEM. Dois animais de cada grupo foram eutanasiados. Lesões microscópicas foram ob- 
servadas nos bezerros do G2. Histologicamente as alterações observadas foram necrose neuronal cortical e lesões hemorrágicas nos núcleos basais, tálamo, mesencéfalo, ponte e bulbo. O protocolo experimental constituído por uma dieta rica em carboidrato de alta fermentação, baixa quantidade de fibra efetiva e altos níveis de enxofre $(0,52 \%)$ ocasionou alterações clinicas e histológicas e elevadas concentrações de sulfeto de hidrogênio ruminal compatíveis com quadro de intoxicação por enxofre.

TERMOS-INDEXAÇÃO: Necrose cerebrocortical, enxofre, bovinos, modelo experimental, sulfeto de hidrogênio ruminal.

\section{INTRODUÇÃO}

Polioencefalomalacia (PEM) é uma doença cerebrocortical degenerativa dos ruminantes sendo o termo utilizado para indicar necrose laminar do córtex cerebral possuindo vários fatores associados a sua ocorrência (Gould 1998, Gould 2000, Cebra \& Cebra 2004, Burgess 2008, Sant'Ana et al. 2009a,b).

Na literatura internacional uma das principais causas de PEM relatada tem sido a intoxicação por enxofre (Raisbeck 1982, Gunert al. 1987, Gooneratne et al. 1989, Sager et al. 1990, Gould et al. 1991, Hamlen et al. 1993, Jeffrey et al. 1994, McAllister et al. 1997, Loneragan et al. 1998, Gould 1998, Gould 2000, Niles et al. 2000, Loneragan et al. 2001, Niles et al. 2002, Haydock 2003, Loneragan et al. 2005, Kul et al. 2006, Dewhurst et al. 2007, McKenzie et al. 2009). Outras etiologias descritas foram deficiência da tiamina (Jensen et al. 1956, Edwin \& Jackman 1973), intoxicação por cloreto de sódio associada à privação de água (Trueman \& Clague 1978, Osweiler et al. 1995), intoxicação por chumbo (Christian \& Tryphonas 1971), ingestão de melaço (Mella et al. 1976) ou de plantas ricas em tiaminases (Pritchard \& Eggleston 1978) e infecção por herpesvírus bovino 5 (BoHV-5) (Perez et al. 2003, Rissi et al. 2008).

No Brasil, existem relatos de surtos de PEM em bovinos ocasionados por intoxicação por cloreto de sódio associada à privação de água (Lemos et al. 1997, Nakazato et al. 2000), intoxicação por chumbo (Lemos et al. 2004, Traverso et al. 2004), forma aguda da intoxicação por Phalaris spp. (Souza \& Irigoven 1999) e infecção pelo BoHV-5 (Salvador et al. 1998, Sanches et al. 2000, Claus et al. 2002, Colodel et al. 2002, Elias et al. 2004, Riet-Correa et al. 2006, Barros et al. 2006, Mendes et al. 2007, Rissi et al. 2006, 2007, 2008, Lunardi et al. 2009). O diagnóstico de PEM no Brasil já foi anteriormente sugerido ou associado a distúrbio no metabolismo da tiamina (Santos et al. 1983, Gonçalves et al. 2001, Mendes et al. 2007), intoxicação por enxofre (Traverso et al. 2001, Lima et al. 2005) e alterações bruscas na dieta (Moro et al. 1994). Estes diagnósticos foram estabelecidos correlacionando dados epidemiológicos, sinais neurológicos, achados histopatológicos e/ou resposta favorável à terapia com tiamina, sendo que as etiologias não foram confirmadas laboratorialmente.

A necessidade da melhor compreensão da etiopatogenia da PEM no Brasil tem estimulado o estabelecimento de modelos experimentais em ruminantes. Em um estudo experimental foi demonstrado que bovinos que tinham sido inoculados anteriormente com BoHV-5 desenvolviam meningoencefalite após a indução de PEM mediante a administração de amprólio ou sulfato de sódio (David et al. 2007). Cunha et al. (2008) induziram PEM em dois bovinos Nelore fornecendo diariamente por via nasoesofágica enxofre a $1 \%$ da matéria seca e Sant'Ana et al. (2009c) intoxicaram cinco ovinos administrando amprólio por via oral em doses diárias de 500 e $1.000 \mathrm{mg} / \mathrm{kg}$ de peso do animal.

Os objetivos desse trabalho foram de avaliar os sinais clínicos, as concentrações do sulfeto de hidrogênio ruminal e as alterações anatomopatológicas associadas à intoxicação experimental por enxofre em bezerros.

\section{MATERIAL E MÉTODOS}

Foram utilizados 10 bezerros mestiços leiteiros, machos, com oito meses de idade, pesando entre $100-120 \mathrm{~kg}$, mantidos durante todo o período experimental em baias individuais. Os animais foram distribuídos aleatoriamente em dois grupos, sendo que quatro bovinos receberam ração sem adição de sulfato de sódio (G1) e seis animais receberam a ração acrescida de sulfato de sódio (G2). O grupo G1 foi constituído pelos Bovinos 3, 5, 10 e 11, e o grupo G2 pelos Bezerros 1, 4, 6, 7, 8 e 9. Na ração do grupo $\mathrm{G} 2$ foi adicionado diariamente como fonte de enxofre, o sulfato de sódio, totalizando um consumo de $0,52 \%$ de enxofre na matéria seca.

O protocolo de intoxicação foi adaptado de Sager et al. (1990) com algumas modificações. O período experimental foi dividido em três fases. A fase 1 constituiu a adaptação dos bovinos com suplementação exclusiva de feno por um período de 14 dias, enquanto a fase 2 compreendeu um período de sete dias de transição do feno para ração, retirando-se $1 / 2 \mathrm{~kg}$ do feno/dia/bezerro e adicionando-se $1 / 2 \mathrm{~kg}$ da ração/dia/bezerro. Na ultima fase (fase 3), os animais receberam exclusivamente ração durante 14 dias. A ingestão do feno coast-cross (Cynodon dactylon) e o consumo da ração foram de $2,5 \%$ do peso animal.

A ração fornecida era constituída por casca de aveia (30\%), farelo de soja (18,5\%), amido (17\%), dextrose (17\%), óleo de milho $(4 \%)$, uréia $(3 \%)$, bicarbonato de sódio $(2 \%)$, fosfato de cálcio $(2,5 \%)$, sulfato de sódio $(0,8 \%)$, cloreto de potássio $(0,5 \%)$, óxido de magnésio $(0,2 \%)$ e água $(4,5 \%)$. Ainda foram incorporados na ração $2.000 \mathrm{UI} / \mathrm{kg}$ vitamina $\mathrm{A}, 100 \mathrm{UI} / \mathrm{kg}$ vitamina D, $20 \mathrm{Ul} / \mathrm{kg}$ vitamina $E, 80 \mathrm{mg} / \mathrm{kg}$ ferro, $40 \mathrm{mg} / \mathrm{kg}$ manganês, $20 \mathrm{mg} / \mathrm{kg}$ zinco, $1 \mathrm{mg} / \mathrm{kg}$ cobalto, $1 \mathrm{mg} / \mathrm{kg}$ iodo e $4 \mathrm{mg} / \mathrm{kg}$ cobre.

As análises bromatológicas do feno de Coast-cross (Cynodon dactylon) (95,33\% matéria seca; 10,28\% proteína bruta; $6,35 \%$ extrato etéreo; $4,54 \%$ minerais; $33,98 \%$ fibra bruta; $44,85 \%$ extrato não nitrogenado; $63,5 \%$ nutrientes digestíveis totais; $76,89 \%$ fibra detergente neutra; $40,7 \%$ fibra detergente ácida) e da ração (90,45\% matéria seca; $21,19 \%$ proteína bruta; $4,31 \%$ extrato etéreo; $10,7 \%$ minerais; $3,92 \%$ fibra bruta; $59,88 \%$ extrato não nitrogenado; $87,27 \%$ nutrientes digestíveis totais; 29,34\% fibra detergente neutra; $13,25 \%$ fibra detergente ácida) foram realizadas no Laboratório de Bromatologia do Departamento de Melhoramento e Nutrição Animal da Faculdade de Medicina Veterinária e Zootecnia da Universidade Estadual Paulista "Júlio de Mesquita Filho" (FMVZ/Unesp-Botucatu).

As análises de elementos minerais do feno de Coast-cross (Cynodon dactylon) (14g/kg de nitrogênio, $1,1 \mathrm{~g} / \mathrm{kg}$ de fósforo, 
$15 \mathrm{~g} / \mathrm{kg}$ de potássio, $2 \mathrm{~g} / \mathrm{kg}$ cálcio, $1,0 \mathrm{~g} / \mathrm{kg}$ de magnésio, $3,5 \mathrm{~g} / \mathrm{kg}$ de enxofre, $14 \mathrm{mg} / \mathrm{kg}$ de boro, $9 \mathrm{mg} / \mathrm{kg}$ de cobre, $190 \mathrm{mg} / \mathrm{kg}$ de ferro, $156 \mathrm{mg} / \mathrm{kg}$ de manganês e $16 \mathrm{mg} / \mathrm{kg}$ de zinco) e da ração $(3,32 \mathrm{~g} / \mathrm{kg}$ de nitrogênio, $5 \mathrm{~g} / \mathrm{kg}$ de fósforo, $6,5 \mathrm{~g} / \mathrm{kg}$ de cálcio, $2,2 \mathrm{~g} / \mathrm{kg}$ de magnésio, $940 \mathrm{mg} / \mathrm{kg}$ de enxofre, $227,5 \mathrm{mg} / \mathrm{kg}$ de ferro, $80 \mathrm{mg} / \mathrm{kg}$ de manganês, $0,80 \mathrm{mg} / \mathrm{kg}$ de selênio, $20 \mathrm{mg} / \mathrm{kg}$ de cobre, $77,5 \mathrm{mg} / \mathrm{kg}$ de zinco, $5,5 \mathrm{~g} / \mathrm{kg}$ de sódio, $35 \mathrm{mg} / \mathrm{kg}$ de boro e $2,5 \mathrm{mg} / \mathrm{kg}$ de molibdênio) foram realizadas, respectivamente, nos Laboratórios de Nutrição Mineral de Plantas do Departamento de Recursos Naturais e Ciência do Solo da Faculdade de Ciências Agronômicas da UNESP/Botucatu e no Instituto Campineiro de Análise de Solo e Adubo Ltda. A dosagem de enxofre da água (11 mg/L) do poço semi-artesiano foi conduzida no Laboratório de Fertilizantes e Corretivos da Faculdade de Ciências Agronômicas da UNESP/Botucatu.

Os animais foram colocados em tronco de contenção para a realização do exame físico. Em seguida, foram obtidas amostras de sangue para a realização de hemograma e avaliação do fibrinogênio e proteína plasmáticas, de gás ruminal para determinar as concentrações do sulfeto de hidrogênio ruminal $\left(\mathrm{H}_{2} \mathrm{~S}\right.$ ou gás sulfídrico) e o fluido ruminal para aferir o $\mathrm{pH}$ ruminal. Os animais foram monitorados diariamente para detecção de sinais clínicos encefálicos. O exame físico, as dosagens de gás sulfídrico ruminal e as colheitas das amostras de sangue e líquido ruminal foram realizadas com intervalos de sete ou 14 dias (Quadro 1) para evitar estresse de manejo e interferência no consumo da ração. No final da fase 3 foram colhidas amostras do líquido cefalorraquidiano (LCR) dos Bovinos 4, 6, 7, 8 e 9 (G2).

As amostras de sangue total foram colhidas, por venopunção da jugular, em tubos contendo anticoagulante (EDTA) e submetidas à contagem de células em câmara hematimétrica de Neubauer, à determinação do volume globular pelo método do microhematócrito e à dosagem de hemoglobina pelo método da cianometahemoglobina, calculando-se posteriormente os índices hematimétricos (volume globular médio e concentração de hemoglobina globular média). A contagem diferencial de leucócitos foi realizada em 100 células em esfregaços sanguíneos corados pelo panótico rápido ${ }^{4}$. Para a mensuração do fibrinogênio utilizou-se a técnica de precipitação no tubo de microhematócrito a $56^{\circ} \mathrm{C}$ e a proteína foi determinada diretamente pela refratometria (Coles 1984).

A técnica da dosagem de sulfeto de hidrogênio ruminal utilizada foi adaptada de Gould et al. (1997) com as modificações descritas a seguir. Inicialmente foi realizada a tricotomia da fossa paralombar esquerda e anti-sepsia com iodopovidona (PVPI), sendo que a punção ruminal foi realizada no ponto médio da porção mais dorsal da fossa paralombar esquerda utilizando-se a agulha do cateter intravenoso 14G sem a cânula externa de teflon. Em seguida, foi encaixado ao conector da

\section{Quadro 1. Momentos em que foram realizados os exames físicos, as colheitas de amostras de sangue total e de fluido ruminal e as dosagens de sulfeto de hidrogênio ruminal $\left(\mathrm{H}_{2} \mathrm{~S}\right)$ dos bovinos do grupo que ingeriu ração sem sulfato de sódio (G1) e com sulfato de sódio (G2) nas três fases do protocolo de indução experimental de polioence- falomalacia}

\begin{tabular}{ccccc}
\hline Fases & $\begin{array}{c}\text { Exame físico } \\
\text { (dia) }\end{array}$ & $\begin{array}{c}\text { Sangue } \\
\text { (dia) }\end{array}$ & $\begin{array}{c}\mathrm{H}_{2} \mathrm{~S} \text { ruminal } \\
\text { (dia) }\end{array}$ & $\begin{array}{c}\text { Fluido ruminal } \\
\text { (dia) }\end{array}$ \\
\hline 1 & $1^{\circ}, 7^{\circ}$ e $14^{\circ}$ & $1^{\circ}$ e $14^{\circ}$ & $1^{\circ}, 7^{\circ}$ e $14^{\circ}$ & $1^{\circ}, 7^{\circ}$ e $14^{\circ}$ \\
2 & $7^{\circ}$ & $7^{\circ}$ & $7^{\circ}$ & $7^{\circ}$ \\
3 & $7^{\circ}$ e $14^{\circ}$ & $14^{\circ}$ & $3^{\circ}, 7^{\circ}, 10^{\circ}$ e $14^{\circ}$ & $7^{\circ}$ e $14^{\circ}$
\end{tabular}

agulha um equipo de infusão intravenosa com $15 \mathrm{~cm}$ de comprimento, cortando e desprezando-se a extremidade com o gotejador. A ponta cortada do equipo adaptado foi acoplada a um tubo colorimétrico de dosagem de gás sulfídrico, que já estava previamente inserido na bomba manual de vácuo ${ }^{5}$. As mensurações foram realizadas de acordo com o manual do fabricante da bomba de vácuo, utilizando tubos colorimétricos para valores entre 25 e 1.000 ppm $^{6}$ ou 1.000 a 40.000 ppm $^{7}$ de sulfeto de hidrogênio. Nos momentos em que não ocorreu mudança na coloração do tubo, repetiu-se a dosagem e não se detectando alteração foi estabelecido que o valor aferido estivesse abaixo do limite inferior de detecção do tubo (<25ppm de $\mathrm{H}_{2} \mathrm{~S}$ ruminal).

As amostras do conteúdo ruminal foram obtidas por meio de uma bomba de sucção a vácuo, acoplada a um recipiente de vidro e a uma sonda oroesofágica tipo Schambye e Sorensen (Dirksen et al. 1993). Para a avaliação do $\mathrm{pH}_{\text {ruminal }}{ }^{8}$ os primeiros $200 \mathrm{~mL}$ foram desprezados para evitar contaminação com a saliva, sendo colhidos aproximadamente $100 \mathrm{~mL}$ de cada animal.

As coletas de LCR foram realizadas segundo protocolo proposto por Mayhew (1989). Após sedação com 0,20 mg/kg/ IV de cloridrato de xilazina ${ }^{9}$, tricotomia e anti-sepsia com PVPI, a punção foi realizada na cisterna atlanto-occipital com agulha spinal $^{10}$.

As amostras de LCR foram coletadas em três tubos estéreis sem EDTA. Para análise do LCR foi utilizada uma fração da amostra do terceiro tubo. O número de leucócitos e hemácias por microlitro do LCR foi mensurado com o uso da câmara de Fuchs-Rosenthal. A contagem diferencial de leucócitos foi feita em lâminas preparadas por citocentrifugação ${ }^{11}$ e coradas pelo panótico rápido. As proteínas ${ }^{12}$ e a glicose ${ }^{13}$ foram dosadas com kits comerciais, empregando o método colorimétrico, cujas leituras das reações foram feitas em espectrofotômetro ${ }^{14}$.

\footnotetext{
4 Instant Prov, Newprov Produtos para Laboratório, Av. Primeiro de Maio 590, Pinhais, PR.

5 Bomba modelo AP-20S, Sensidyne ${ }^{\circledR}$, Sensidyne Industrial Health and Safety Instrumentation, Clearwater, Florida, USA. Representante no Brasil: Almont do Brasil, Rua Horácio de Castilho 284, Vila Maria Alta, São Paulo, SP.

${ }^{6}$ Tubos colorimétricos modelo $120 \mathrm{SF}$, Sensidyne ${ }^{\circledR}$, Sensidyne Industrial Health \& Safety Instrumentation, Clearwater, Florida, USA. Representante no Brasil: Almont do Brasil, Rua Horácio de Castilho 284, Vila Maria Alta, São Paulo, SP.

7 Tubos colorimétricos modelo $120 \mathrm{SH}$, Sensidyne ${ }^{\circledR}$, Sensidyne Industrial Health \& Safety Instrumentation, Clearwater, Florida, USA. Representante no Brasil: Almont do Brasil, Rua Horácio de Castilho 284, Vila Maria Alta, São Paulo, SP.

8 Phtek®, modelo pH100, Tecnoglobo equipamentos para laboratório, Rua Holanda 1166, Bairro Boa Vista, Curitiba, PR.

${ }^{9}$ Vibaxil $2 \%$, Virbac Saúde Animal, Av. Engenheiro Eusébio Stevaux 1368, Jurubatuba, SP.

${ }^{10}$ BD Spinal 20G x 31/2", Becton Dickison Ind. Cirúrgicas Ltda, Av. Pres. Juscelino Kubitschek 273, Juiz de Fora, MG.

11 Citocentrífuga Citológica Microprocessada modelo 200D, Cientec Equipamentos para Laboratórios, Rua Buenos Aires 717, Parque Água Branca, Piracicaba, SP.

12 Sensiprot, Labtest Diagnóstica, Av. Paulo Ferreira da Costa 600, Lagoa Santa, MG.

13 Glicose, Labtest Diagnóstica, Av. Paulo Ferreira da Costa 600, Lagoa Santa, MG.

${ }^{14}$ Espectrofotômetro Digital B 44242, Micronal, Rua João Rodrigues Machado 25, Brooklin, São Paulo, SP.
} 
O bovino que morreu naturalmente (Bezerro 1) e os animais submetidos à eutanásia (Bezerros 4, 5, 7 e 10) foram necropsiados. A eutanásia foi realizada utilizando cloridrato de xilazina $(0,10 \mathrm{mg} / \mathrm{kg} / \mathrm{IV})$, tiopental sódico $(8 \mathrm{mg} / \mathrm{kg} / \mathrm{IV})$ e por último cloreto de potássio.

Amostras de tecido hepático e renal do Animal 10 do grupo G1 e dos Bovinos 1, 4 e 7 do grupo G2 foram coletadas para dosagem de chumbo por espectrofotometria por absorção atômica no Centro de Assistência Toxicológica (CEATOX) do Instituto de Biociências da Unesp-Botucatu.

Uma porção do córtex frontal do Bezerro 1 foi colhida para realizar a técnica da PCR para diagnóstico diferencial do herpesvírus bovino 5 . O processo de extração de DNA foi realizado a partir de $20 \mathrm{mg}$ da amostra de encéfalo utilizando kit de extração ${ }^{15}$. A técnica da PCR foi realizada segundo Claus et al. (2005) com algumas modificações. Os "primers" utilizados foram B5 (senso) específico para BoHV-5 (5'- CGG ACG AGA CGC CCT TGG-3' NT 322-339) e primer anti-senso denominado Bcon (5'-AGT GCA CGT ACA GCG GCT CG-3' NT 519538), que amplificaram fragmento com $159 \mathrm{pb}$ do gene da glicoproteína $\mathrm{C}$ do BoHV-5. Como controle positivo utilizou-se amostra AA PAR do BoHV-5, isolada do cérebro de um bovino apresentando sinais de encefalite cedida pelo Laboratório de Virologia Animal do Centro de Ciências Agrárias da Universidade Estadual de Londrina. Realizou-se a PCR com a enzima GoTaq $^{\circledR}$ Green Master Mix ${ }^{16}$. A reação foi padronizada para um volume final de 50il e possuía 0,4ì de cada oligonucleotídeo iniciador (senso e anti-senso), 5il de DNA, 25il GoTaq ${ }^{\circledR}$ Green Master Mix, $8 \% \mathrm{DMSO}^{17} \mathrm{e}$ água "nuclease-free" q.s.p. O processo de amplificação foi realizado em termociclador ${ }^{18}$ de acordo com as seguintes condições de tempo e temperatura: 1 ciclo de 2 min. a $95^{\circ} \mathrm{C}$ seguido por 40 ciclos de 40 segundos a $94^{\circ} \mathrm{C}$ (denaturação), $1 \mathrm{~min}$. com temperatura de hibridização de $57,8^{\circ} \mathrm{C}, 1$ min. a $72^{\circ} \mathrm{C}$ (extensão) e um ciclo de extensão final de $5 \mathrm{~min}$. a $72^{\circ} \mathrm{C}$. Os produtos amplificados foram analisados por eletroforese em gel de agarose a 1,5\%, corado com GelRed ${ }^{\text {TM }} 19$ e visualizado sob luz ultra-violeta. Os géis foram documentados no ImageQuant $\AA^{20}$.

Os fragmentos encefálicos (porção occipital do telencéfalo, tálamo, vermix do cerebelo e a porção final do tronco encefálico do Bezerro 1 foram congelados e encaminhados para exame de imunofluorescência direta para diagnóstico diferencial de raiva no Departamento de Higiene e Saúde Pública da FMVZ/Unesp-Botucatu.

O exame macroscópico sob aplicação da luz ultra-violeta no comprimento de $365 \mathrm{~nm}$ (lâmpada de Wood) foi realizado na porção do córtex frontal dos Bezerros 1, 4 e 7 do grupo G2, de acordo com Edwin \& Jackman (1981).

${ }^{15}$ QIAamp ${ }^{\circledR}$ DNA Mini Kit (cat no 51304), Qiagen Biotecnologia Brasil Ltda, Av. Jabaquara 1909, São Paulo, SP.

${ }^{16}$ Promega, Madison, WI, EUA. Representante no Brasil: Prodimol Biotecnologia, Praça Carlos Chagas 49, Santo Agostinho, Belo Horizonte, MG.

17 Dimetilsulfóxido (DMSO), Sigma-Aldrich $®$. Representante no Brasil: Interjet produtos para laboratório, Rua Sobrália 254, Vila Gea, São Paulo,SP.

${ }^{18}$ Mastercycler@ ep Eppendorf. Eppendorf Brasil, Rua Ferreira Araújo 221, São Paulo, SP

19 Biotium, Halward, CA, EUA. Representante no Brasil: Uniscence do Brasil, Av. Cândido Portinari 933/93, São Paulo, SP.

20 GE Healthcare. Ge Healthcare Life Sciences do Brasil, Av. Paulista 37, Bairro Bela Vista, São Paulo, SP.
Para o exame histopatológico foram colhidas as seguintes porções do sistema nervoso central (SNC): bulbo olfatório, córtex frontal (anterior) na altura do joelho do corpo caloso, córtex occipital (posterior), córtex parietal (dorso-lateral), núcleos basais, tálamo, mesencéfalo na altura dos colículos rostrais, ponte com pedúnculos cerebelares, bulbo na altura do óbex e cerebelo. Adicionalmente foram examinados em monobloco o gânglio de Gasser (trigêmeo), rete mirabile e hipófise (GRH). As amostras foram fixadas em formol tamponado a $10 \%$ para a realização do exame histopatológico.

$\mathrm{Na}$ análise histopatológica, a intensidade das lesões foi estabelecida considerando lesão discreta (1) quando menos de $25 \%$ do tecido estava afetado, moderada (2) referente a alterações de 25 a 50\% e acentuadas (3) indicando comprometimento acima de $50 \%$ do tecido avaliado. Os seguintes aspectos foram computados para a obtenção da intensidade das lesões: hemorragia, congestão, edema do neurópilo, infiltrado inflamatório, meningite, gliose focal, gliose difusa, neurônios vermeIhos (neurônios com o citoplasma encolhido e eosinofílico e núcleo picnótico), neuronofagia, malacia (necrose do componente neuroectodérmico com manutenção das estruturas mesenquimais e infiltrado de macrófagos tumefeitos e com citoplasma espumoso [células Gitter]), e lesão residual (estruturas vasculares e células Gitter remanescentes, formando uma estrutura cavitária semelhante a um cisto). Cada um dos aspectos avaliados foi relacionado à seção anatômica examinada, com o objetivo de determinar a localização das lesões produzidas pela doença no SNC. Adicionalmente, foram avaliados qualitativamente o tipo de infiltrado inflamatório e a presença de corpúsculos de inclusão intranucleares característicos de herpesvírus (Rissi et al. 2006, Sant'Ana et al. 2009a).

Os resultados da temperatura retal, frequência cardíaca e respiratória, motricidade ruminal, do hemograma, do fibrinogênio plasmático, da proteína plasmática, do $\mathrm{pH}$ ruminal e do líquido cefalorraquidiano foram submetidos à análise descritiva, constituída pelo cálculo das médias aritméticas e dos desvios-padrão. A média e os desvios padrão para o parâmetro da determinação da concentração do sulfeto de hidrogênio ruminal foram calculados e submetidos à análise estatística no programa GraphPad InStat versão 3.0 para Windows (GraphPad Software) e foram avaliadas por análise de variância (ANOVA), seguido pelo teste de Tukey. Diferença estatística foi considerada para $p \geq 0,05$ (Sampaio 1998). Para realização da análise estatística foi considerado o valor de 24 ppm nas aferições referentes aos valores inferiores a $25 \mathrm{ppm}$ do sulfeto de hidrogênio ruminal.

Todos os procedimentos realizados estavam de acordo com as normas e princípios éticos de experimentação animal, estabelecidos pela Câmara de Ética em Experimentação Animal da FMVZ/UNESP/Botucatu, sendo o experimento aprovado pela mesma (Protocolo $\left.n^{\circ} 117 / 2006-C E E A\right)$.

\section{RESULTADOS E DISCUSSÃO}

O período inicial de 15 dias (fase 1) foi importante porque proporcionou a adaptação dos animais nas baias, facilitando o manejo dos mesmos no tronco para a realização dos exames físicos e colheita das amostras para a execução dos exames complementares propostos. $\mathrm{Na}$ fase 2, a mudança gradativa no intervalo de sete dias da dieta contendo feno para alimentação exclusivamente com ração, não ocasionou distúrbios metabólicos como acidose ruminal. 
A composição e a proporção dos ingredientes da ração do presente estudo, bem como os resultados da análise bromatológica e mineral foram muito similares à ração experimental utilizada por Sager et al. (1990) no protocolo de indução por PEM por ingestão excessiva de enxofre.

Para cálculo do consumo de enxofre pelos bovinos na fase 1 , verificou-se que a ingestão do feno foi de $2,5 \%$ do peso vivo representando a ingestão de $0,35 \%$ de enxofre na matéria seca. Para o cálculo da ingestão de enxofre na água foi estimado que um bovino de $120 \mathrm{~kg}$ mantido em temperatura ambiente de $28^{\circ} \mathrm{C}$ deve ingerir aproximadamente 20 litros de água por dia (Gould 2000), totalizando o consumo de $220 \mathrm{mg}$ de enxofre por dia $(0,022 \%$ de enxofre). A ingestão de enxofre na água e feno na fase 1 totalizou o consumo de $0,37 \%$ na matéria seca, valor este acima do nível recomendado (0,15\%) por Klasing et al. (2005). Este alto consumo de enxofre na matéria seca ocorreu porque o valor determinado no feno estava o dobro do descrito como normal por Valadares Filho (2006). A explicação para incremento do enxofre no feno pode ser justificada pela intensa adubação com sulfato de amônio realizada pela empresa que comercializou o volumoso objetivando aumentar o seu valor nutritivo. O sulfato de amônio quando utilizado como fertilizante proporciona aumento na concentração de enxofre na forragem (Arthington et al. 2002) e melhora a digestibilidade da fibra em detergente ácido e da fibra em detergente neutro das forragens cultivadas nestes solos, quando fornecida aos ruminantes (Ahmad et al. 1995).

Na fase 3, para o grupo G1, o cálculo do consumo de enxofre foi baseado na ingestão de $2,5 \%$ do peso vivo da matéria seca da ração $(0,09 \%$ de enxofre na matéria seca) somado ao da água $(0,022 \%$ de enxofre por dia), totalizando, aproximadamente, $0,11 \%$ de enxofre na matéria seca. Para o grupo G2, acrescentou-se o sulfato de sódio na ração como fonte de enxofre, que somado à ingestão do enxofre na água totalizou $0,52 \%$ de enxofre na matéria seca. O estabelecimento do nível tóxico na dieta fornecida para os bovinos do grupo G2 foi baseado nas recomendações do Klasing et al. (2005), que preconizaram o valor de tolerância máxima de enxofre de $0,30 \%$ para dietas compostas com mais de $85 \%$ de concentrado.

A temperatura retal e a frequência cardíaca estavam dentro dos valores considerados normais por Radostits et al. (2007). Entretanto, episódios de taquipnéia foram observados nos Bezerros 3 e 5 do grupo $\mathrm{G} 1$ e nos animais 4 e 8 do grupo G2 na fase de adaptação e na fase 3 somente no grupo G2 (Bezerros 4 e 8). Sager et al. (1990) e Gould et al. (1997) ao induzirem PEM com protocolo semelhante ao do presente estudo observaram episódios transitórios de taquipnéia nos bezerros ao ingerirem ração com excesso de enxofre. Os resultados das induções experimentais e as descrições de surtos de PEM por enxofre indicaram que antes dos animais apresentarem sinais neurológicos, a temperatura retal e as frequências cardíaca e respiratória podem estar alteradas (Gunn et al. 1987, Mckenzie et al. 2009) ou não (Loneragan et al. 1998, Haydock 2003). Nos ruminantes, $60 \%$ dos gases eructados podem ser inalados, favorecendo a exposição do trato respiratório ao gás sulfídrico durante episódios de produção exagerada de sulfeto de hidrogênio ruminal, podendo ocasionar alterações respiratórias em bovinos (Kung et al. 1998), justificando os episódios de taquipnéia observados na fase 3 nos Bezerros 4 e 8 do grupo G2.

Com relação à motricidade ruminal (Quadro 2), nos dois grupos experimentais observou-se valores normais (Dirksen et al. 1993) somente na primeira fase. A hipomotricidade ruminal observadas nas fases 2 e 3, em ambos os grupos, não foi relatada por Gould et al. (1997), mas estes autores observaram em alguns animais timpanismo gasoso. A hipomotricidade ruminal constatada na fase 2 ocorreu devido à baixa quantidade de fibra oferecida, enquanto que na fase 3 pelo fornecimento de dieta contendo exclusivamente ração. A motricidade ruminal é estimulada pela presença de fibra efetiva (Dirksen et al. 1993).

Os resultados do eritrograma (Quadro 3), leucograma (Quadro 4), do fibrinogênio plasmático e proteína plasmática (Quadro 5) estavam dentro dos valores de referência citados por Radostits et al. (2007). Loneragan et al. (1998) relataram surto de PEM em bezerros de corte recém desmamados e confinados ocasionado pela ingestão excessiva de enxofre na matéria seca $(0,9 \%)$ e também não observaram alterações nos resultados do leucograma, fibrinogênio e da proteína plasmática. Entretanto, Gunn et al. (1987) relataram surto de PEM ocasionado por flor de

Quadro 2. Valores médios e desvios-padrão $(\bar{x} \pm \sigma)$ da temperatura retal $\left({ }^{\circ} \mathrm{C}\right)$, frequência cardíaca (batimentos/min.) e respiratória (movimentos/min.) e motricidade ruminal (movimentos/cinco min.) aferidas nas três fases do protocolo de indução de polioencefalomalacia nos bezerros do grupo que ingeriu ração sem sulfato de sódio (G1) e com sulfato de sódio (G2)

\begin{tabular}{|c|c|c|c|c|c|c|c|c|}
\hline & \multicolumn{2}{|c|}{ Temperatura retal } & \multicolumn{2}{|c|}{ Frequência cardíaca } & \multicolumn{2}{|c|}{ Frequência respiratória } & \multicolumn{2}{|c|}{ Motricidade ruminal } \\
\hline & G1 & G2 & G1 & G2 & G1 & G2 & G1 & G2 \\
\hline $\begin{array}{c}\text { Fase } 1 \\
1^{\circ} \text { dia }\end{array}$ & $39 \pm 0,3$ & $3816+0.5$ & $662+23$ & $7033+54$ & $44+43$ & $22+91$ & $875+05$ & $85+15$ \\
\hline $7^{\circ}$ dia & $38,72 \pm 0,2$ & $39,41 \pm 0,6$ & $65,5 \pm 1,9$ & $65 \pm 6,1$ & $37 \pm 10,5$ & $37,6 \pm 6,3$ & $7,5 \pm 0,5$ & $8 \pm 0,6$ \\
\hline $14^{\circ} \mathrm{dia}$ & $38,6 \pm 0,5$ & $39,15 \pm 0,3$ & $64,7 \pm 2,6$ & $66,66 \pm 4,8$ & $30,75 \pm 10,6$ & $38,33 \pm 6,9$ & $8,5 \pm 0,6$ & $8,3 \pm 1,5$ \\
\hline $\begin{array}{c}\text { Fase } 2 \\
7^{\circ} \text { dia }\end{array}$ & 39 & $39,44 \pm 0,3$ & $70 \pm 8,2$ & $66,4 \pm 6,8$ & $31,75 \pm 5$ & $38,4 \pm 7,2$ & $5,25 \pm 0,5$ & $4,2 \pm 1,0$ \\
\hline Fase 3 & & & & & & & & \\
\hline $7^{\circ} \mathrm{dia}$ & $38,42 \pm 0,2$ & $39,26 \pm 0,1$ & $69,2 \pm 11,6$ & $76,4 \pm 6,0$ & $30,25 \pm 5,18$ & $39,6 \pm 6,0$ & $3 \pm 0,8$ & $3,2 \pm 0,4$ \\
\hline $14^{\circ} \mathrm{dia}$ & $37,85 \pm 0,2$ & $39,28 \pm 0,2$ & $66,5 \pm 4,4$ & $74 \pm 10,7$ & $30 \pm 2,16$ & $47,6 \pm 18,1$ & $1,5 \pm 0,5$ & $1,8 \pm 0,8$ \\
\hline
\end{tabular}


Quadro 3. Valores médios e desvios-padrão $(\bar{x} \pm \sigma)$ dos eritrogramas avaliados nas três fases do protocolo de indução de polioencefalomalacia nos bezerros do grupo que ingeriu ração sem sulfato de sódio (G1) e com sulfato de sódio (G2)

\begin{tabular}{|c|c|c|c|c|c|c|c|c|c|c|}
\hline & \multicolumn{2}{|c|}{$\begin{array}{l}\text { Hemácias } \\
\left(\times 10^{6} / \mathrm{mm}^{3}\right)\end{array}$} & \multicolumn{2}{|c|}{$\begin{array}{l}\text { Hemoglobina } \\
\text { (g/DI) }\end{array}$} & \multicolumn{2}{|c|}{$\begin{array}{c}\text { Volume globular } \\
\qquad(\%)\end{array}$} & \multicolumn{2}{|c|}{ VGM(FI) } & \multicolumn{2}{|c|}{ CHGM(\%) } \\
\hline & G1 & G2 & G1 & G2 & G1 & G2 & G1 & G2 & G1 & G2 \\
\hline $\begin{array}{c}\text { Fase } 1 \\
1^{\circ} \mathrm{dia} \\
14^{\circ} \mathrm{dia}\end{array}$ & $\begin{array}{l}6,78 \pm 0,5 \\
6,18 \pm 0,6\end{array}$ & $\begin{array}{l}6,81 \pm 1,1 \\
6,08 \pm 0,3\end{array}$ & $\begin{array}{l}9,72 \pm 1,2 \\
9,35 \pm 1,5\end{array}$ & $\begin{array}{c}10,56 \pm 1,1 \\
9,32 \pm 0,5\end{array}$ & $\begin{array}{l}29,25 \pm 3,7 \\
29,2 \pm 5,67\end{array}$ & $\begin{array}{l}32,16 \pm 3,3 \\
29,66 \pm 2,0\end{array}$ & $\begin{array}{l}43,07 \pm 3,1 \\
47,10 \pm 5,5\end{array}$ & $\begin{array}{l}48,01 \pm 7,0 \\
48,93 \pm 0,9\end{array}$ & $\begin{array}{c}33,24 \pm 0,1 \\
32,1 \pm 1,5\end{array}$ & $\begin{array}{l}32,18 \pm 1,4 \\
31,60 \pm 0,9\end{array}$ \\
\hline $\begin{array}{l}\text { Fase } 2 \\
7^{\circ} \text { dia }\end{array}$ & $6,37 \pm 0,6$ & $6,49 \pm 0,5$ & $9,3 \pm 1,0$ & $9,76 \pm 1,0$ & $28 \pm 3,5$ & $29,8 \pm 2,7$ & $43,9 \pm 2,9$ & $45,89 \pm 1,6$ & $33,2 \pm 1,4$ & $32,71 \pm 0,7$ \\
\hline
\end{tabular}

Quadro 4. Valores médios e desvios-padrão $(\bar{x} \pm \sigma)$ dos leucogramas avaliados nas três fases do protocolo de indução de polioencefalomalacia nos bezerros do grupo que ingeriu ração sem sulfato de sódio (G1) e com sulfato de sódio (G2)

\begin{tabular}{|c|c|c|c|c|c|c|c|c|c|c|}
\hline & \multicolumn{2}{|c|}{$\begin{array}{l}\text { Leucócitos } \\
\left(\times 10^{3} / \mathrm{mm}^{3}\right)\end{array}$} & \multicolumn{2}{|c|}{$\begin{array}{l}\text { Segmentados } \\
\left(\times 10^{3} / \mathrm{mm}^{3}\right)\end{array}$} & \multicolumn{2}{|c|}{$\begin{array}{c}\text { Linfócitos } \\
\left(\times 10^{3} / \mathrm{mm}^{3}\right)\end{array}$} & \multicolumn{2}{|c|}{$\begin{array}{l}\text { Eosinófilos } \\
\left(\times 10^{3} / \mathrm{mm}^{3}\right)\end{array}$} & \multicolumn{2}{|c|}{$\begin{array}{l}\text { Monócitos } \\
\left(\times 10^{3} / \mathrm{mm}^{3}\right)\end{array}$} \\
\hline & G1 & G2 & G1 & G2 & G1 & G2 & G1 & G2 & G1 & G2 \\
\hline $\begin{array}{c}\text { Fase } 1 \\
1^{\circ} \mathrm{dia} \\
14^{\circ} \mathrm{dia}\end{array}$ & $\begin{array}{l}9,03 \pm 1,0 \\
7,57 \pm 0,8\end{array}$ & $\begin{array}{l}8,0 \pm 1,73 \\
8,14 \pm 2,3\end{array}$ & $\begin{array}{c}2,38 \pm 0,3 \\
1,8 \pm 1,1\end{array}$ & $\begin{array}{l}2,05 \pm 0,8 \\
2,27 \pm 1,0\end{array}$ & $\begin{array}{l}6,33 \pm 0,9 \\
5,65 \pm 0,8\end{array}$ & $\begin{array}{l}5,5 \pm 1,63 \\
5,39 \pm 1,4\end{array}$ & $\begin{array}{l}0,33 \pm 0,1 \\
0,1 \pm 0,04\end{array}$ & $\begin{array}{c}0 \\
0,15 \pm 0,04\end{array}$ & $\begin{array}{l}0,13 \pm 0,05 \\
0,07 \pm 0,01\end{array}$ & $\begin{array}{l}0,11 \pm 0,09 \\
0,08 \pm 0,03\end{array}$ \\
\hline $\begin{array}{l}\text { Fase } 2 \\
7^{\circ} \text { dia }\end{array}$ & $6,6 \pm 1,3$ & $7,74 \pm 1,7$ & $1,17 \pm 0,3$ & $1,69 \pm 0,4$ & $5,35 \pm 1,2$ & $5,75 \pm 1,7$ & 0,12 & 1,24 & 0,12 & $0,07 \pm 0,01$ \\
\hline $\begin{array}{l}\text { Fase } 3 \\
14^{\circ} \text { dia }\end{array}$ & $6,67 \pm 1,4$ & $7,46 \pm 2,1$ & $1,47 \pm 0,3$ & $1,55 \pm 0,5$ & $5,14 \pm 1,4$ & $5,39 \pm 1,26$ & 0,06 & $0,11 \pm 0,05$ & 0 & $0,10 \pm 0,02$ \\
\hline
\end{tabular}

Quadro 5. Valores médios e desvios-padrão $(\bar{x} \pm \sigma)$ do fibrinogênio plasmático $(\mathrm{g} / \mathrm{dL})$ e proteína plasmática $(\mathrm{mg} /$ $\mathrm{dL}$ ) avaliados nas três fases do protocolo de indução de polioencefalomalacia nos bezerros do grupo que ingeriu ração sem sulfato de sódio (G1) e com sulfato de sódio (G2)

\begin{tabular}{|c|c|c|c|c|}
\hline & \multicolumn{2}{|c|}{$\begin{array}{l}\text { Fibrinogênio plasmático } \\
(\mathrm{mg} / \mathrm{dL})\end{array}$} & \multicolumn{2}{|c|}{$\begin{array}{c}\text { Proteína plasmática } \\
(\mathrm{g} / \mathrm{dL})\end{array}$} \\
\hline & G1 & G2 & G1 & G2 \\
\hline $\begin{array}{c}\text { 'Fase } 1 \\
1^{\circ} \mathrm{dia} \\
14^{\circ} \mathrm{dia}\end{array}$ & $\begin{array}{l}150 \pm 57,7 \\
250 \pm 100\end{array}$ & $\begin{array}{c}300 \pm 109,5 \\
266,66 \pm 103,2\end{array}$ & $\begin{array}{c}8,1 \pm 0,2 \\
7,15 \pm 0,34\end{array}$ & $\begin{array}{l}6,88 \pm 0,2 \\
6,33 \pm 0,7\end{array}$ \\
\hline $\begin{array}{l}\text { Fase } 2 \\
7^{\circ} \text { dia }\end{array}$ & $250 \pm 100$ & $440 \pm 89,4$ & $6,9 \pm 0,11$ & $7,0 \pm 0,2$ \\
\hline $\begin{array}{l}\text { Fase } 3 \\
14^{\circ} \text { dia }\end{array}$ & $450 \pm 100$ & $360 \pm 89,4$ & $7,65 \pm 0,3$ & $6,84 \pm 0,1$ \\
\hline
\end{tabular}

enxofre e observaram leucocitose por neutrofilia em alguns bezerros. McKenzie et al. (2009) realizaram exames hematológicos em bovinos com PEM devido a ingestão de Raphanus raphanistrum que continha elevado teor de enxofre $(0,62 \%)$ e identificaram no eritrograma aumento da hemoglobina, do volume globular e do número de hemácias, possivelmente devido a desidratação e leucocitose com hiperfibrinogemia, indicando processo inflamatório.

Durante o período experimental somente um bezerro apresentou anormalidades encefálicas. No sexto dia da fase 2, o Bezerro 1 do grupo G2 apresentou apatia, ataxia, tremor de cabeça e nistagmo vertical com evolução aguda, levando cerca de 10 horas desde o inicio dos sinais até a morte. Observações de sinais neurológicos seme-
Ihantes foram relatados por Gould (2000), Cebra \& Cebra (2004), Burgess (2008) e Sant'Ana et al. (2009a,b).

Sager et al. (1990) observaram sinais neurológicos em apenas cinco de 14 bovinos alimentados com dieta semeIhante ao da presente pesquisa, mas com teor de enxofre inferior $(0,26 \%)$. Os sinais neurológicos nos animais foram identificados sete dias após o inicio do fornecimento da ração e caracterizados, inicialmente, por apatia, com evolução para ataxia, amaurose, pressão da cabeça contra objetos e andar compulsivo. Gould et al. (1991) forneceram dieta semelhante ao do presente trabalho e observaram sinais neurológicos similares aos descritos por Sager et al. (1990), mas em cinco de nove bovinos após três dias da introdução da ração com $0,36 \%$ de enxofre na matéria seca. Em outro estudo desenvolvido por Gould et al. (1997) com dieta semelhante a anterior, os autores identificaram amaurose e ataxia em três bovinos de um lote de quatro animais após dois dias do fornecimento da dieta contendo $0,41 \%$ de enxofre na matéria seca. Na presente pesquisa ao fornecer ração com $0,52 \%$ de enxofre acreditava-se que o número de animais doentes seria maior quando comparado com os resultados obtidos por Sager et al. (1990) e Gould et al. (1991, 1997), que suplementaram os bovinos com teores inferiores de enxofre e obtiveram maiores taxas de morbidade. Entretanto, os autores citados anteriormente não observaram quadro clínico com evolução aguda como identificado no bezerro 1. Provavelmente estas diferenças estejam associadas ao tipo de grupo genético empregado, pois, no protocolo experimental utilizado por Gould et al.(1997) foram utilizados animais Bos 
Quadro 6. Valores médios e desvios-padrão $(\bar{x} \pm \sigma)$ do sulfeto de hidrogênio ruminal (ppm) avaliados nas três fases do protocolo de indução de polioencefalomalacia nos bezerros do grupo que ingeriu ração sem sulfato de sódio (G1) e com sulfato de sódio (G2)

\begin{tabular}{|c|c|c|}
\hline & G1 & G2 \\
\hline \multicolumn{3}{|l|}{ Fase 1} \\
\hline $1^{\circ} \mathrm{dia}$ & $24 \mathrm{Aa}$ & $46 \pm 51 \mathrm{Aa}$ \\
\hline $7^{\circ} \mathrm{dia}$ & $1.300 \pm 621,82 \mathrm{Ba}$ & $128,83 \pm 149,99 \mathrm{Aa}$ \\
\hline $14^{\circ}$ dia & $1.725 \pm 618,46 \mathrm{Ba}$ & $1.255 \pm 928,15 \mathrm{Aa}$ \\
\hline \multicolumn{3}{|l|}{ Fase 2} \\
\hline $7^{0}$ dia & $47,25 \pm 35,45 \mathrm{Aa}$ & $803,33 \pm 610,39 \mathrm{Aa}$ \\
\hline \multicolumn{3}{|l|}{ Fase 3} \\
\hline 3o dia & $73,5 \pm 44,22 \mathrm{Aa}$ & $3.900 \pm 1.282,57 \mathrm{Bb}$ \\
\hline $7^{\circ} \mathrm{dia}$ & $50,5 \pm 53 \mathrm{Aa}$ & $3.900 \pm 2.284,73 \mathrm{Bb}$ \\
\hline $10^{\circ} \mathrm{dia}$ & $205 \pm 57,44 \mathrm{Aa}$ & $3.960 \pm 1.289,57 \mathrm{Bb}$ \\
\hline $14^{\circ} \mathrm{dia}$ & $49,75 \pm 20,82 \mathrm{Aa}$ & $3.240 \pm 1.533,94 \mathrm{Bb}$ \\
\hline
\end{tabular}

Letras maiúsculas diferentes nas colunas indicam diferença significativa $(p<0,05)$ entre as fases do período experimental.

Letras minúsculas diferentes nas linhas indicam diferença significativa $(p<0,05)$ entre os grupos G1e G2.

taurus, enquanto no presente estudo foram avaliados bovinos mestiços leiteiros. Pesquisas comparativas entre Bos taurus e Bos indicus sugerem que há diferenças entre os dois grupos quanto à ingestão alimentar e eficiência de utilização de rações com alta ou baixa densidade de energia (Putrino et al. 2007).

Os valores de gás sulfídrico ruminal (Quadro 6) da fase 1 referente à primeira dosagem dos dois grupos experimentais e da segunda aferição ( $7^{\circ}$ dia) do grupo G2 estavam dentro da faixa de normalidade para a espécie (inferior a 500ppm) determinada por Burgess (2008). Ainda na fase 1 , observou-se que na segunda aferição ( $7^{\circ}$ dia) do $\mathrm{H}_{2} \mathrm{~S}$ ruminal do grupo $\mathrm{G} 1$ e na terceira (14을 dia) dos dois grupos experimentais, os valores foram superiores aos considerados normais e corroboraram com os resultados de Cunha et al. (2008), que detectaram elevados teores de gás sulfídrico ruminal (5000ppm) em bovinos alimentados exclusivamente com feno que continha também elevados teores de enxofre na análise mineral foliar. Acredita-se que a ingestão de $0,37 \%$ de enxofre na matéria seca tenha proporcionado os elevados valores de gás sulfídrico ruminal nos animais suplementados exclusivamente com volumoso (fase 1), justificando a importância da determinação deste elemento na dieta (Gould 2000), especialmente no Brasil, onde diversos surtos de PEM foram relatados, mas a etiologia não foi esclarecida (Lemos 2005, Lima et al. 2005). Sant'Ana et al. (2009a) ao realizar estudo retrospectivo de 31 casos naturais de PEM em bovinos do Rio Grande do Sul e do Centro-Oeste brasileiro relataram a possibilidade de que alguns dos casos descritos estariam associados à intoxicação por enxofre, embora essa hipótese não tenha sido confirmada laboratorialmente.

Após o início do fornecimento da ração (fase 3), os bovinos que receberam sulfato de sódio (G2) apresentaram valores de $\mathrm{H}_{2} \mathrm{~S}$ ruminal acima do considerado normal (Burgess 2008), enquanto no grupo G1 os valores foram

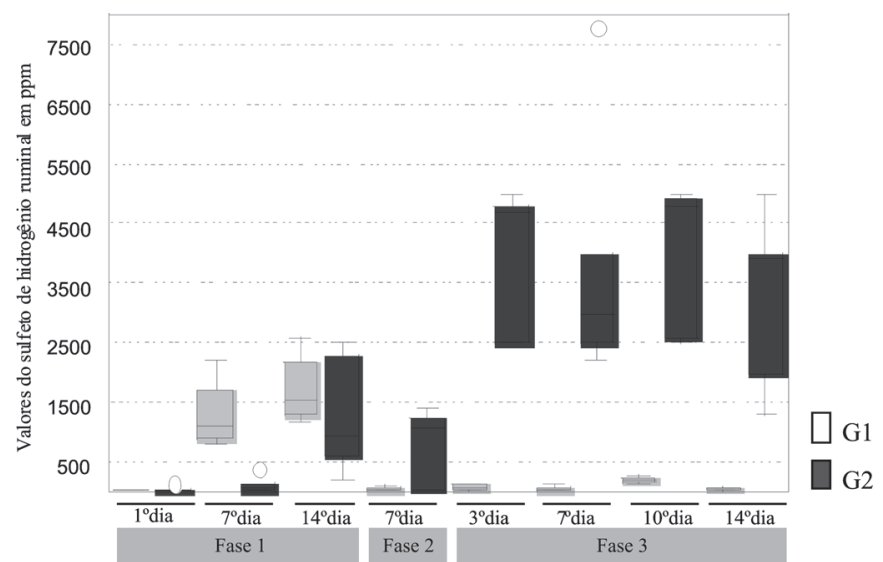

Fig.1. Box plot dos valores do sulfeto de hidrogênio ruminal (ppm) aferidos nas três fases do protocolo de indução de polioencefalomalacia nos bezerros mestiços dos grupos que ingeriram ração sem (G1) e com sulfato de sódio(G2).

inferiores a 280ppm (Fig.1). Com relação aos valores médios do gás sulfídrico foram verificadas diferenças significativas $(p<0,05)$ no $G 1$ no $7^{\circ}$ e $14^{\circ}$ dias da fase 1 ao comparar com os demais momentos e, no G2, entre as fases 1 e 2 ao comparar com a fase 3 . Além disso, foi observada diferença significativa $(p<0,05)$ entre os grupos $G 1$ e G2 somente na fase 3 (Quadro 6). Em determinados momentos, os valores de $\mathrm{H}_{2} \mathrm{~S}$ ruminal do $\mathrm{G} 2$ foram 100 vezes superior aos do $\mathrm{G} 1$, indicando que o sulfeto de hidrogênio ruminal é um produto normal do metabolismo da microbiota ruminal, mas quando os bovinos consomem dietas com alto teor de enxofre, ocorre produção excessiva $\mathrm{de}_{2} \mathrm{~S}$ no rúmen podendo ocasionar a PEM (Gould 2000). Altos valores de gás sulfídrico ruminal, em bovinos que ingeriram elevadas quantidades de enxofre, também foram descritos por Loneragan et al. (1998), Niles et al. (2002), Loneragan et al. (2005) e Cunha et al. (2008).

Gould et al. (1997) ao compararem a técnica da dosagem de gás sulfídrico ruminal utilizando tubos colorimétricos com a cromatografia líquida de alta eficiência, não observaram diferenças significativas entre os resultados obtidos, confirmando que a metodologia empregada no presente estudo reflete valores confiáveis da concentração de $\mathrm{H}_{2} \mathrm{~S}$ ruminal, sendo desnecessário o uso de outras técnicas para este propósito.

Variações nos valores do sulfeto de hidrogênio ruminal entre os animais do mesmo grupo e na mesma fase do protocolo experimental também foram relatadas por Niles et al. (2002), que induziram PEM em novilhas fornecendo dieta constituída por $70 \%$ de farelo de glúten de milho e $30 \%$ de casca de algodão associado com sulfato de sódio em três diferentes concentrações, todas acima do recomendado por Klasing et al. (2005). Isto indica que o metabolismo ruminal do enxofre é rápido e que as concentrações do gás sulfídrico ruminal são dinâmicas e se modificam rapidamente em resposta ao consumo de enxofre e a capacidade de absorção pela parede do rúmen (Loneragan et al. 1998). 
Gould et al. (1997), Gould (2000) e Burgess (2008) enfatizaram que o odor de ovo em putrefação produzido pela eructação do gás sulfídrico ruminal foi associado ao aparecimento da PEM. Coghlin (1944) ao detectar odor pútrido de ovo em decomposição estabeleceu como causa do surto a ingestão excessiva de enxofre pelos bovinos. Apesar dos elevadores teores de sulfeto de hidrogênio ruminal detectado em todos os animais do G2, especialmente na fase 3 , em nenhum momento foi identificado esse tipo de odor nos animais do presente trabalho.

Várias investigações têm focado a associação entre a PEM e as altas concentrações do gás sulfídrico ruminal (Gould et al. 1991, Gould et al. 1997, McAllister et al. 1997, Niles et al. 2002, Cunha et al. 2008). A dosagem do sulfeto de hidrogênio ruminal do Bezerro 1, no momento em que o mesmo apresentava sinais neurológicos compatíveis com PEM, foi de 1250ppm, valor este 2,5 vezes acima do considerado normal por Burgess (2008). Apesar de Gould et al. (1997) e Loneragan et al. (1998) descreverem que em bezerros submetidos a dietas com excesso de enxofre, o aparecimento dos sinais clínicos coincide com o aumento dos valores do sulfeto de hidrogênio ruminal, no presente estudo notou-se isto em apenas um bezerro, enquanto que nos outros animais mesmo apresentando elevadas concentrações de sulfeto de hidrogênio ruminal não foi identificada alteração neurológica no exame clínico.

A determinação do gás sulfídrico ruminal tem sido importante nas investigações dos surtos de PEM porque elevadas concentrações do sulfeto de hidrogênio ruminal indicam participação do enxofre na etiopatogenia desta encefalopatia (Loneragan et al. 1998). A técnica de dosagem de sulfeto de hidrogênio ruminal pelos tubos colorimétricos utilizada neste estudo e por Gould et al. (1997), Niles et al. (2002) e Cunha et al. (2008, 2009a,b) demonstrou ser uma ferramenta útil para monitorar situações de risco e auxiliar no diagnóstico definitivo da PEM por enxofre, podendo ser perfeitamente utilizada à campo. A utilização desta técnica associada à análise de enxofre na dieta, pastos, água e suplementos (Gould 2000) estabeleceriam a participação do enxofre nos casos de PEM no Brasil (Lima et al. 2005), bem como auxiliaria no diagnóstico diferencial de outras causas de encefalopatias (Barros et al. 2006).

Os valores médios do $\mathrm{pH}$ do fluido ruminal dos animais dos dois grupos experimentais (Quadro 7), independente da fase, variaram de 6,2 a 7,1 e foram similares aos resultados descritos por Gould et al. (1997). A determinação do $\mathrm{pH}$ ruminal de bovinos confinados submetidos a protocolos de indução experimental deve ser realizada para descartar a possibilidade da ocorrência da PEM por alteração no metabolismo da tiamina devido ao consumo excessivo de ração, que pode diminuir o $\mathrm{pH}$. Na presente pesquisa, mesmo oferecendo na fase 3 uma dieta exclusivamente com ração, o menor valor aferido do $\mathrm{pH}$ ruminal foi de 6,2 para um animal, excluindo a possibilidade da ocorrência de acidose, pois, de acordo com Owens (2007), o pH de fluido ruminal abaixo de 5,6 indica acidose crônica, enquanto inferior a 5,2 sugere acidose aguda.
Quadro 7. Valores médios e desvios-padrão $(\bar{x} \pm \sigma)$ do $\mathrm{pH}$ ruminal avaliados nas três fases do protocolo de indução de polioencefalomalacia nos bezerros do grupo que ingeriu ração sem sulfato de sódio (G1) e com sulfato de sódio (G2)

\begin{tabular}{lll}
\hline G1 & pH ruminal \\
\cline { 2 - 3 } & & $\mathrm{G} 2$ \\
\hline
\end{tabular}

$\begin{array}{ccc}\text { Fase } 1 & & \\ 1^{\circ} \text { dia } & 7,06 \pm 0,12 & 6,90 \pm 0,23 \\ 7^{\circ} \text { dia } & 6,91 \pm 0,20 & 6,88 \pm 0,34 \\ 14^{\circ} \text { dia } & 6,59 \pm 0,22 & 6,73 \pm 0,16 \\ \text { Fase } 2 & & \\ 7^{\circ} \text { dia } & 6,56 \pm 0,24 & 6,78 \pm 0,16 \\ \text { Fase3 }^{\circ} \text { dia } & 6,8 \pm 0,32 & \\ \text { 14ㅇ }^{\circ} & 7,15 \pm 0,19 & 6,66 \pm 0,21 \\ \end{array}$

Quadro 8. Valores individuais da contagem das hemácias, do total e diferencial das células nucleadas, dos teores de glicose $(\mathrm{mg} / \mathrm{dL})$ liquórica e proteína $(\mathrm{mg} / \mathrm{dL})$ das amostras do líquido cefalorraquidiano colhidas no final da 3 fase do protocolo de indução de polioencefalomalacia nos bezerros do grupo que consumiu ração com sulfato de sódio (G2)

\begin{tabular}{lccccc}
\hline \multirow{1}{*}{ Parâmetros } & \multicolumn{5}{c}{ Bovinos (G2) } \\
\cline { 2 - 6 } & 4 & 6 & 7 & 8 & 9 \\
\hline Hemácias (células/ $\mu \mathrm{L})$ & $<1$ & 2 & 13 & 24 & $<1$ \\
Células nucleadas (células/ $\mu \mathrm{L})$ & 1 & 6 & $<1$ & 2 & $<1$ \\
Neutrófilos (\%) & 2 & 0 & 4 & 0 & 0 \\
Células mononucleares (\%) & 5 & 6 & 4 & 8 & 1 \\
Linfócitos (\%) & 2 & 40 & 92 & 48 & 0 \\
Macrófagos (\%) & 3 & 54 & 0 & 44 & 0 \\
Glicose (mg/dL) & 51 & 32 & 33 & 33 & 41 \\
Proteínas totais (mg/dL) & 28,1 & 17,5 & 15,2 & 34,6 & 13,3
\end{tabular}

O Quadro 8 apresenta os resultados da análise do LCR dos Bezerros 4, 6, 7, 8 e 9 do grupo G2. O LCR do Bezerro 1 não foi colhido porque a evolução dos sinais neurológicos foi aguda. As contagens totais e diferenciais das células, assim como as concentrações da glicose e da proteína estão dentro dos valores de referência (Stöber 1993). O aumento na contagem total das células e na concentração da proteína são as alterações mais marcantes no LCR de animais com PEM (Cebra \& Cebra 2004). Loneragan et al. (1998) ao analisarem o LCR de um animal que havia ingerido dieta rica em enxofre $(0,9 \%$ matéria seca) e com sinais neurológicos, detectaram aumento da concentração das proteínas (149 mg/dL) e discreta pleocitose (12 leucócitos $/ \mu \mathrm{L}$ ), sendo que $90 \%$ eram células mononucleares, $6 \%$ linfócitos e $4 \%$ neutrófilos.

No Brasil, a raiva é a enfermidade neurológica mais frequentemente diagnosticada nos bovinos revelando a importância sócio-econômica e de saúde pública das enfermidades que acometem o SNC (Galiza et al. 2010). No diagnóstico diferencial das neuropatias dos bovinos, além da raiva, deve-se também incluir todas as causas de PEM (Barros et al. 2006). O exame de imunofluorescência direta para raiva foi negativo para o Bezerro 1, assim como não foi identificada a presença do DNA do BoHV-5 realizado por meio da técnica da PCR. Além disso, as concentra- 
Quadro 9. Valores individuais da dosagem de chumbo realizada nos fragmentos de tecido hepático $(\mu \mathrm{g} / \mathrm{g})$ e renal $(\mu \mathrm{g} / \mathrm{g})$ colhidas do bezerro 10 do grupo que ingeriu ração sem sulfato de sódio (G1) e dos bezerros 1,4 e 7 do que consumiram ração com sulfato de sódio (G2)

\begin{tabular}{lccccc}
\hline \multicolumn{1}{c}{ Tecido } & $\mathrm{G} 1$ & & \multicolumn{3}{c}{$\mathrm{G} 2$} \\
\cline { 2 - 2 } \cline { 5 - 6 } & 10 & & 1 & 4 & 7 \\
\hline Hepático $(\mu \mathrm{g} / \mathrm{g})$ & 0,24 & & $<0,05$ & 0,068 & 0,27 \\
Renal $(\mu \mathrm{g} / \mathrm{g})$ & 0,13 & & $<0,05$ & 0,05 & 0,16
\end{tabular}

ções de chumbo nas amostras de tecido hepático e renal (Quadro 9) nos Bezerros 1, 4, 7 e 10 estavam abaixo dos níveis considerados tóxicos (Lemos \& Riet-Correa 2007).

As alterações macroscópicas do encéfalo observadas no Bezerro 1 indicaram edema do córtex parietal e occipital esquerdo, caracterizado por tumefação com achatamento dos giros cerebrais, sendo que este tipo de lesão foi também descritos em casos naturais (Hamlen et al. 1993, Loneragan et al. 1998, Haydock 2003, Kul et al. 2006) e experimentais (Gould et al. 1991, 1997) de PEM por enxofre. No mesmo animal observou-se que a tumefação do córtex parietal e occipital ocasionou compressão da porção lateral esquerda do cerebelo (Fig.2), porém não foi suficiente para o animal desenvolver opistótono. Acreditase que neste animal não ocorreu o deslocamento caudal (herniação) do bulbo e do cerebelo no sentido do forame magno, conforme citado por Loneragan et al. (1998) e Kul et al. (2006) porque a evolução clínica foi aguda.

No encéfalo dos animais 5 e 10 sacrificados do grupo G1 e dos Bezerros 4 e 7 do grupo G2 não foram observadas lesões macroscópicas, mas a ocorrência destas depende da severidade e duração do quadro clínico (Sant'Ana et al. 2009a). Áreas de hemorragia no encéfalo são observadas macroscopicamente, principalmente no telencéfalo e tálamo, em surtos de PEM ocasionados por excesso de enxofre detectado em diferentes fontes, como água (Hamlen et al. 1993, Haydock 2003), feno e água (Loneragan et al. 1998) e cevada de malte (Kul et al. 2006).

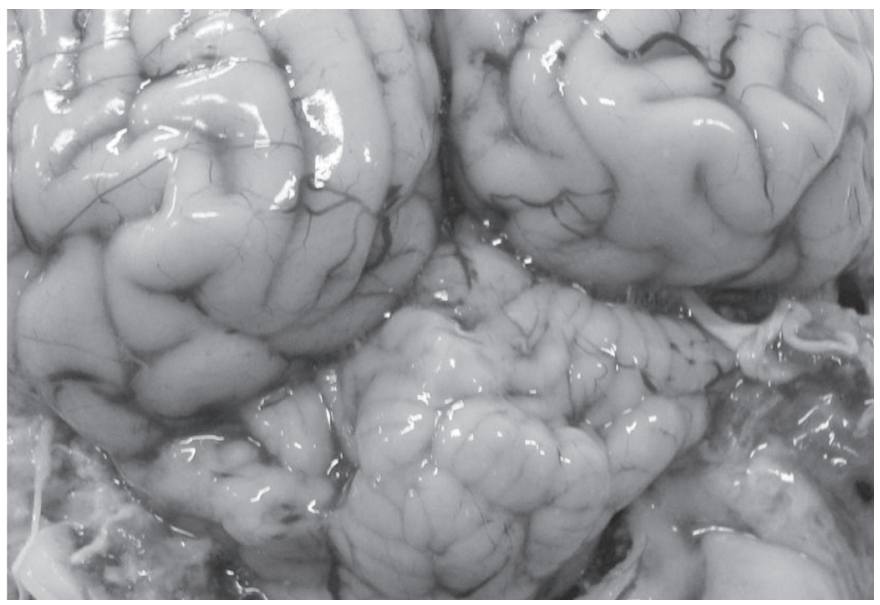

Fig.2. Tumefação com achatamento dos giros dos córtex parietal e occipital (especialmente do hemisfério esquerdo) comprimindo a porção lateral esquerda do cerebelo (Bezerro 1).
O exame macroscópico sob aplicação pela lâmpada de Wood foi realizado conforme recomendado por Edwin \& Jackman (1981) no encéfalo dos Bezerros 1, 4 e 7 do grupo G2 e não foi evidenciada a autofluorescência. Jeffrey et al. (1994), Gould et al. (1997), McAllister et al. (1997), Loneragan et al. (1998) e Haydock (2003) evidenciaram autofluorescência nos cérebros dos animais que desenvolveram sinais neurológicos e no exame histopatológico identificaram malacia no córtex referente as áreas de autofluorescência. Acredita-se que a fluorescência seja devido a metabólitos lipídicos em macrófagos (Little 1978) ou material semelhante a colágeno de alto peso molecular (Edwin \& Jackman 1981). Para Loneragan et al. (1998), o exame de autofluorescência indica fortes evidências para o diagnóstico preliminar de PEM.

Nos Bovinos 5 e 10 do grupo G1 não foram observadas alterações histopatológicas. Nos Bovinos 1, 4 e 7 do grupo G2, as lesões microscópicas predominaram no córtex frontal, parietal e occipital e incluíram necrose neuronal (neurônios vermelhos), edema de neurópilo e gliose, concordando com Gould (2000). Estas lesões foram acentuadas no bezerro que apresentou sinais neurológicos (Bezerro 1) (Fig.3) e com menor intensidade (discretas a moderadas) nos Bovinos 4 e 7 do mesmo grupo que não apresentaram sinais clínicos. Somente no Bezerro 1 foram observadas alterações discretas, incluindo necrose neuronal e edema, nos núcleos basais (Fig.4), tálamo (Fig.5) e mesencéfalo. Em nenhum animal foi observado infiltrado de macrófagos espumosos (células Gitter), manguitos perivasculares e lesões no cerebelo e no complexo gânglio de Gasser, rete mirabile e hipófise. Hemorragias discretas foram observadas no mesencéfalo do Bovino 4 e no bulbo (Fig.6) do Bovino 7. Necrose neuronal cortical associada a lesões no tálamo, ponte e bulbo como as descritas nesta pesquisa foram evidenciados nos casos naturais de PEM ocasionadas por enxofre (Hamlen et al. 1993, Jeffrey et al. 1994, Loneragan et al. 1998) e na indução experimental realizada por Cunha et al. (2008). Para Hamlen et al. (1993), Jeffrey et al. (1994) e Loneragan et al. (1998), lesões hemorrágicas em estrutu-

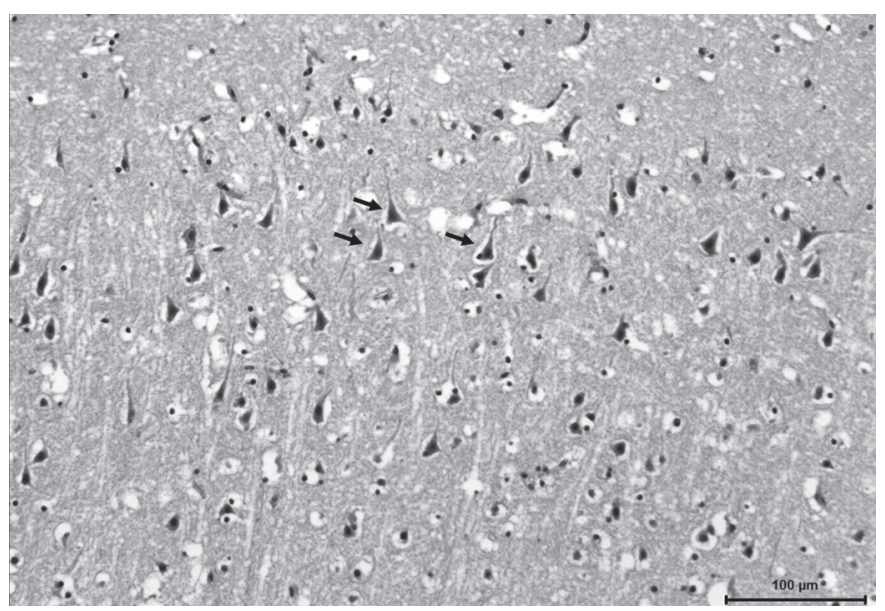

Fig.3. Neurônios vermelhos (setas) no córtex parietal esquerdo (Bezerro 1). HE, obj.20x. 


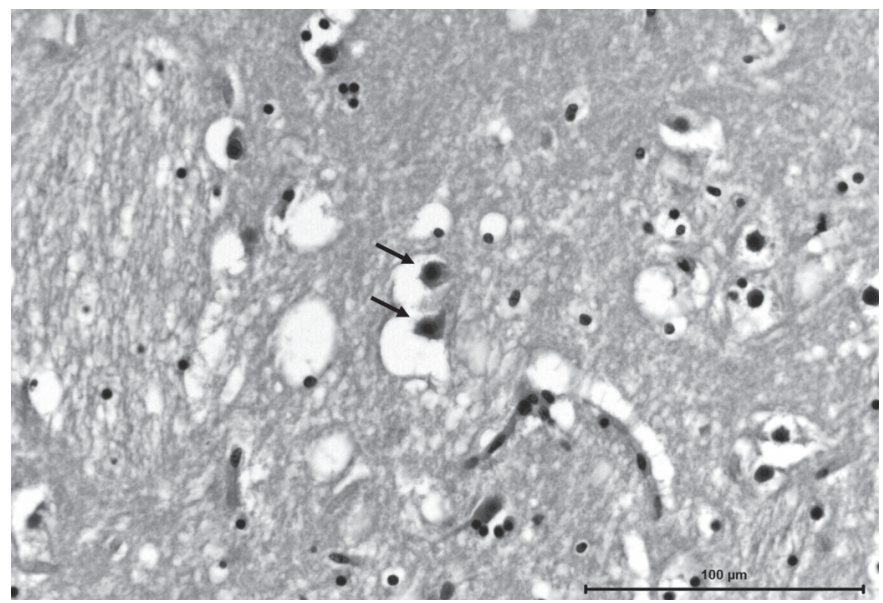

Fig.4. Edema (vacúolos) e necrose neuronal (setas) nos núcleos da base (Bezerro 1). HE, obj.40x.

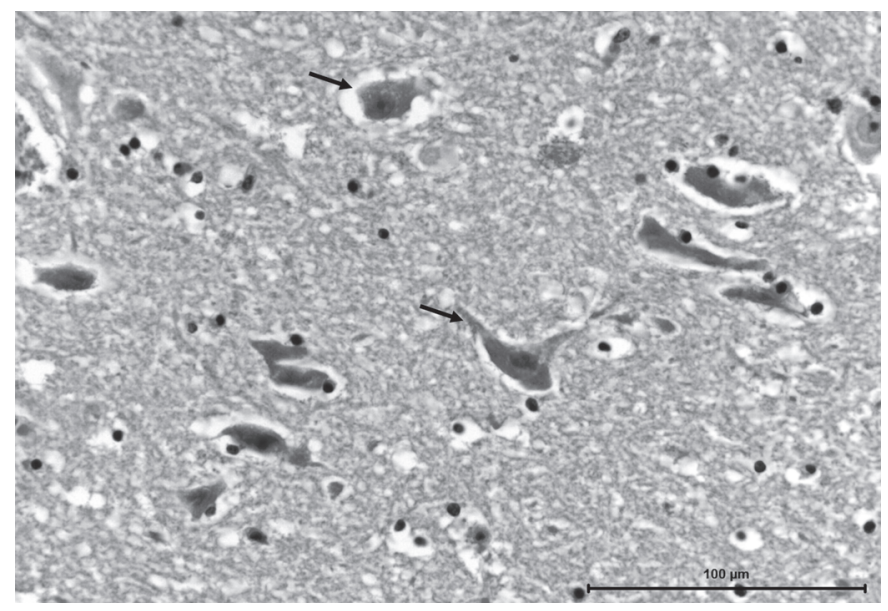

Fig.5. Neurônios vermelhos (setas) no tálamo (Bezerro 1). HE, obj.40x.

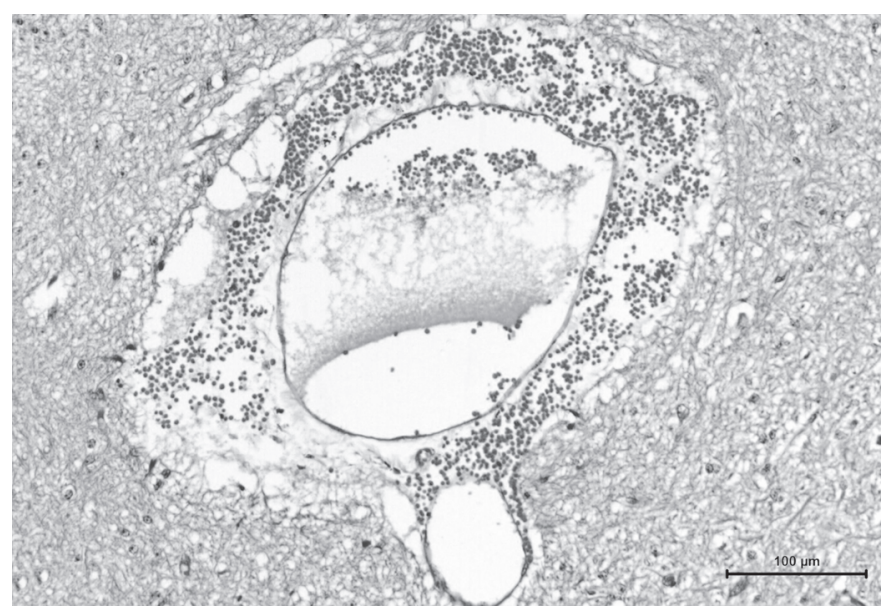

Fig.6. Área de hemorragia discreta perivascular no bulbo (Bezerro 7). HE, obj.20x.

ras mais ventrais do encéfalo como tálamo, ponte e bulbo associadas com necrose cortical podem auxiliar no diagnóstico diferencial da PEM por enxofre daquela ocasionada por deficiência de tiamina. Lesões corticais de PEM em associação a alterações em estruturas ventrais do encéfalo também foram detectadas em casos naturais da doença em bovinos do Brasil (Sant'Ana et al. 2009a).

Necrose fibrinóide de pequenas arteríolas no tálamo e mesencéfalo (Hamlen et al. 1993) e hemorragias focais no tálamo e mesencéfalo secundárias a degeneração de veias e vênulas (Loneragan et al. 1998) foram descritas em dois surtos de PEM por enxofre. No presente trabalho, discreta hemorragia no mesencéfalo somente foi identificada em um bezerro do G2. Possivelmente, este tipo de anormalidade não foi constante, pois o consumo de enxofre na dieta $(0,52 \%)$ foi inferior ao dos dois estudos. Os animais dos surtos diagnosticados por Hamlen et al. (1993) e Loneragan et al. (1998) ingeriram respectivamente, 0,70\% e $0,90 \%$ de enxofre na matéria seca. Para Loneragan et al. (1998) a detecção de lesões profundas no encéfalo pode ser uma conseqüência da exposição a elevadas quantidades de sulfeto de hidrogênio, determinada pela quantidade de enxofre ingerido.

A identificação de alterações histológicas sugestivas de PEM em animais que não apresentam alterações neurológicas, mas com elevados valores de sulfeto de hidrogênio ruminal, como observada nos Bovinos 4 e 7 do grupo G2, também foram relatadas por Niles et al. (2002).

O protocolo utilizado no presente estudo baseado no fornecimento de uma dieta rica em enxofre foi eficaz na indução de PEM em bovinos. Além disso, para estabelecer o diagnóstico definitivo da PEM por enxofre ficou evidenciado a importância de se utilizar na rotina métodos complementares, tais como, dosagem de gás sulfídrico ruminal, detecção do DNA do BoHV-5 pela PCR, imunofluorescência direta para raiva, determinação da concentração do chumbo nos fragmentos de tecido hepático e renal e do enxofre na dieta associados ao exame histopatológico.

A necessidade de aumentar a produtividade da bovinocultura no país tem exigido a utilização de novas estratégias nutricionais, como a utilização de dietas ricas em energia e pobre em fibra associada com o uso de subprodutos da agroindústria. Consequentemente criamse condições de risco para a ocorrência da PEM por enxofre, estimulando o desenvolvimento de pesquisas com o estabelecimento de modelos experimentais que permitem melhor compreensão da etiopatogenia da PEM no Brasil.

\section{CONCLUSÃO}

O protocolo experimental constituído por uma dieta rica em carboidrato de alta fermentação, baixa quantidade de fibra efetiva e altos níveis de enxofre $(0,52 \%)$ ocasionou alterações clinicas e histológicas e elevadas concentrações de sulfeto de hidrogênio ruminal compatíveis com quadro de intoxicação por enxofre.

Agradecimentos.- Às acadêmicas Ana Claudia Gorino e Mariana Fontanetti Marinheiro do Curso de Medicina Veterinária da Faculdade de Medicina Veterinária e Zootecnia (FMVZ), Universidade Estadual Paulista (Unesp) Campus de Botucatu, pelo auxílio na execução do experimento. 


\section{REFERÊNCIAS}

Arthington J.D., Recheigl J.E., Yost G.P., McDowell L.R. \& Fanning M.D. 2002. Effects of ammonium sulfate fertilization on bahiagrass quality and copper metabolism in grazing beef cattle. J. Anim. Sci. 80:2507-2512.

Ahmad M.R., Allen V.G., Fontenot J.P. \& Hawkins G.W. 1995. Effect of sulfur fertilization on chemical composition, ensiling characteristics, and utilization by lambs of sorghum silage. J. Anim. Sci. 73:1803-1810.

Barros C.S.L., Driemeier D., Dutra I.S. \& Lemos R.A.A. 2006. Doenças do Sistema Nervoso de Bovinos no Brasil. Agnes, São Paulo, p.166-171.

Burgess B.A. 2008. Polioencephalomalacia. Large Anim. Vet. 8:1-6.

Cebra C.K. \& Cebra M.L. 2004. Altered mentation caused by polioencephalomalacia, hypernatremia, and lead poisoning. Vet. Clin. North Am., Food Anim. Pract. 20:287-302.

Christian R.G. \& Tryphonas L. 1971. Lead poisoning in cattle: Brain lesions and hematologic changes. Am. J. Vet. Res. 32:203-216.

Claus P.C., Alfieri A.F. \& Alfieri A.A. 2002. Herpesvírus Bovino Tipo 5 e Meningoencefalite Herpética Bovina. Semina 23:131-141.

Claus M.P., Alfieri A.F., Folgueras-Flatschart A.V., Wosiacki S.R., Médici K.C. \& Alfieri A.A. 2005. Rapid detection and differentiation of bovine herpesvirus 1 and 5 glycoprotein $\mathrm{C}$ gene in clinical specimens by multiplex-PCR. J. Virol. Meth. 128:183-188.

Coghlin C.L. 1944. Hydrogen sulphide poisoning in cattle. Can. J. Comp. Med. 8:111-113.

Coles E.H. 1984. Patologia Clínica Veterinária. $3^{\underline{a}}$ ed. Manole, São Paulo, p.360-400.

Colodel E.M., Nakazato L., Weiblen R., Mello R.M., Silva R.R.P., Souza M.A., Filho J.A.O. \& Caron L. 2002. Meningoencefalite necrosante em bovinos causada por herpesvírus bovino no estado de Mato Grosso, Brasil. Ciência Rural 32:293-298.

Cunha P.H.J., Badial P.R., Oliveira Filho J.P., Amorim R.L., Cagnini D.Q. \& Borges A.S. 2008. Intoxicação experimental por enxofre em bovinos Nelore. Anais $21^{\circ}$ Encontro Nacional de Diagnóstico Veterinário, Campo Grande, MS, p.20-21.

Cunha P.H.J., Badial P.R., Oliveira Filho J.P., Cagnini Q.D., Marinheiro M.F., Gorino A.C. \& Borges A.S. 2009a. Avaliação da concentração do sulfeto de hidrogênio ruminal utilizando tubos colorimétricos em bovinos criados extensivamente. Anais do $8^{\circ}$ Congresso Brasileiro de Buiatria. Belo Horizonte, MG. Ciênc. Anim. Bras. (Supl.1):83-87.

Cunha P.H.J., Delfiol D.J.Z., Cagnini Q.D., Badial P.R., Oliveira Filho J.P., Olivo G., Amorim R.M. \& Borges A.S. 2009b. Identificação molecular do herpesvirus bovino tipo $5 \mathrm{em}$ um bovino confinado associado com diagnóstico diferencial laboratorial de outras causas de polioencefalomalacia. Anais $8^{\circ}$ Congresso Brasileiro de Buiatria, Belo Horizonte, MG. Ciênc. Anim. Bras. (Supl.1):93-98.

David N., Hübner S.O., Riet-Correa F., Danisa H. \& Lemos R.A. 2007. Reactivation of latent bovine herpesvirus type 5 in cattle with polioencephalomalacia induced by ammonium sulphate. Pesq. Vet. Bras. 27:435-441.

Dewhurst R.J., Kim E.J., Evans R.T., Cabrita A.R.J. \& Fonseca A.J.M. 2007. Effects of dietary sulphur sources on concentrations of hydrogen sulphide in the rumen head-space gas of dairy cows. Animal 1:531-535.

Dirksen G., Gründer H.D. \& Stöber M. 1993. Exame Clínico dos Bovinos. $3^{\text {a }}$ ed. Guanabara Koogan, Rio de Janeiro, p.373-381.

Edwin E.E. \& Jackman R. 1973. Ruminal thiaminase and tissue thiamine in cerebrocortical necrosis. Vet. Rec. 92:640-641.

Edwin E.E. \& Jackman R. 1981. Nature of the autofluorescent material in cerebrocortical necrosis. J. Neurochem. 37:1054-1056.

Elias F., Schild A.L. \& Riet-Correa F. 2004. Meningoencefalite e polioencefalomalacia por herpesvírus bovino-5: distribuição das lesões no sistema nervoso central de bovinos naturalmente infectados. Pesq. Vet. Bras. 24:123-131.
Galiza G.J.N., Silva M.L.C.R., Dantas A.F.M., Simões S.V.D., RietCorrea F. 2010. Doenças do sistema nervoso de bovinos no semiárido nordestino. Pesq. Vet. Bras. 30:267-276.

Gonçalves R.C., Viana L., Sequeira J.L., Bandarra E.P., Chiacchio S.B. \& Kuchembuck M.R.G. 2001. Aspectos clínicos, anatomopatológicos e epidemiológicos da polioencefalomalácia em bovinos, na região de Botucatu, SP. Vet. Notícias 7:54-57.

Gooneratne S.R., Olkowski A.A., Klemmer R.G., Kessler G.A. \& Christensen D.A. 1989. High sulfur related thiamine deficiency in cattle: A field study. Can. Vet. J. 30:139-146.

Gould D.H. 1998. Polioencephalomalacia. J. Anim. Sci. 76:309-314.

Gould D.H. 2000. Update on sulphur-related polioencephalomalacia. Vet. Clin. North Am., Food Anim. Pract. 16:481-496.

Gould D.H., McAllister M.M., Savage J.C. \& Hamar D.W. 1991. High sulfide concentrations in rumen fluid associated with nutritionally induced polioencephalomalacia in calves. Am. J. Vet. Res. 52:1164-1169.

Gould D.H., Cummings B.A. \& Hamar D.W. 1997. In vivo indicators of pathologic ruminal sulfide production in steers with diet-induced polioencephalomalacia. J. Vet. Diag. Invest. 9:72-76.

Gunn M.F., Baird J.D. \& Wilkie J.S.N. 1987. Accidental sulfur poisoning in a group of Holstein heifers. Can. Vet. J. 28:188-192.

Hamlen H., Clark E. \& Janzen E. 1993. Polioencephalomalacia in cattle consuming water with elevated sodium sulfate levels: A herd investigation. Can. Vet. J. 34:153-158.

Haydock D. 2003. Sulfur-induced polioencephalomalacia in a herd of rotation cattle. Can. Vet. J. 44:828-829.

Jeffrey M., Duff J.P., Higgins R.J., Simpson V.R., Jackman R., Jones T.O., Mechie S.C. \& Liversey C.T. 1994. Polioencephalomalacia associated with the ingestion of ammonium sulphate by sheep and cattle. Vet. Rec. 134:343-348.

Jensen R., Griner L.A. \& Adams O.R. 1956. Polioencephalomalacia of cattle and sheep. J. Am. Vet. Med. Assoc. 129:311-321.

Klasing K.C., Goff J.P., Greger J.L. \& King J.C. 2005. Mineral Tolerance of Animals. $2^{\text {nd }}$ ed. National Academics Press, Washington DC, p.372385.

Kul O., Karahan S., Basalan M. \& Kabakcl N. 2006. Polioencephalomalacia in cattle: A consequence of prolonged feeding barley malt sprouts. J. Vet. Med. Assoc. 53:123-128.

Kung L., Bracht J.Y. \& Tavares J.Y. 1998. Effects of various compounds on in vitro ruminal fermentation and production of sulfide. Anim. Feed Sci. Technol. 84:69-81.

Lemos R.A.A. 2005. Enfermidades do sistema nervoso de bovinos de corte das regiões Centro-Oeste e Sudeste do Brasil. Tese de Doutorado, Universidade Estadual Paulista, Jaboticabal, SP. 150p.

Lemos R.A.A. \& Riet-Correa F. 2007. Polioencefalomalacia, p.658-670. In: Riet-Correa F., Schild A.L., Lemos R.A.A. \& Borges J.R.J. (Eds), Doenças de Ruminantes e Eqüídeos. Vol.2. 3aㅡ ed. Pallotti, Santa Maria.

Lemos R.A.A., Nakazato L., Barros C.S.L., Gattas C.B.A. \& Bonilla R. 1997. Meningoencefalite eosinofílica em bovinos no estado do Mato Grosso do Sul. Arqs Inst. Biológico, São Paulo, 64(Supl.1):43.

Lemos R.A.A., Driemeier D., Guimarães E.B., Dutra I.S., Mori A.E. \& Barros C.S.L. 2004. Lead poisoning in cattle grazing pasture contaminated by industrial waste. Vet. Hum. Toxicol. 46:326-328.

Lima E.F., Riet-Correa F., Tabosa I.M., Dantas A.F.M., Medeiros J.M. \& Sucupira Júnior G. 2005. Polioencefalomalacia em caprinos e ovinos na região semi-árida do Nordeste do Brasil. Pesq. Vet. Bras. 25:9-14.

Little P.B. 1978. Identity of fluorescence in polioencephalomalacia.Vet. Rec. 103:76.

Loneragan G.H., Gould D.H., Callan R.J., Sigurdson C.J. \& Hamar D.W. 1998. Association of excess sulfur intake and an increase in hydrogen sulfide concentrations in the ruminal gas cap of recently weaned beef calves with polioencephalomalacia. J. Am. Vet. Med. Assoc. 213:1599-1604. 
Loneragan G.H., Wagner J.J., Gould D.H., Garry F.B. \& Thoren M.A. 2001. Effects of water sulfate concentrations on performance, water intake, and carcass characteristics of feedlot steers. J. Anim. Sci. 79:2941-2948.

Loneragan G.H., Gould D.H., Wagner J., Garry F. \& Thoren M. 2005. The magnitude and patterns of ruminal hydrogen sulfide production, blood thiamine concentration, and mean pulmonary arterial pressure in feedlot steers consuming water of different sulfate concentrations. Bovine Pract. 39:16-22.

Lunardi M., Claus M.P., Lisboa J.A.N., Amude A.M., Headley S.A., Alfieri A.F. \& Alfieri A.A. 2009. Neurological and epidemiological aspects of a BoHV-5 meningoencephalitis outbreak. Braz. Arch. Biol. Technol. 52:77-85

McKenzie R.A., Carmichael A.M., Schibrowski M.L., Duigan S.A., Gibson J.A. \& Taylor J.D. 2009. Sulfur-associated polioencephalomalacia in cattle grazing plants in the family Brassicaceae. Aust. Vet. J. 87:27-32.

Mayhew I.G. 1989. Large Animal Neurology: A handbook for veterinary clinics. Lea and Febiger, London, p.49-55.

McAllister M.M., Gould D.H. \& Raisbeck M.F. 1997. Evaluation of ruminal sulfide concentrations and seasonal outbreaks of polioencephalomalacia in beef cattle in a feedlot. J. Am. Vet. Med. Assoc. 211:12751279.

Mella C.M., Perez-Oliva O. \& Loew F.M. 1976. Induction of bovine polioencephalomalacia with feeding system based on molasses and urea. Can. J. Comp. Med. 40:104-110.

Mendes L.C.N., Borges A.S., Peiró J.R., Feitosa F.L.F. \& Anhesini C.R. 2007. Estudo retrospectivo de 19 casos de polioencefalomalácia, em bovinos, responsivos ao tratamento com tiamina. Arq. Bras. Med. Vet. Zootec. 59:239-241.

Moro L., Nogueira R.H.G., Carvalho A.U. \& Marques D.C. 1994. Relato de três casos de polioencefalomalacia em bovinos. Arq. Bras. Med. Vet. Zootec. 46:409-416.

Nakazato L., Lemos R.A.A. \& Riet-Correa F. 2000. Polioencefalomalacia em bovinos nos estados de Mato Grosso do Sul e São Paulo. Pesq. Vet. Bras. 20:119-125.

Niles G.A., Morgan S.E. \& Edwards W.C. 2000. Sulfur-induced polioencephalomalacia in stocker calves. Vet. Human Toxicol. 42:290-291.

Niles G.A., Morgan S., Edwards W.C. \& Lalman D. 2002. Effects of dietary sulfur concentrations on the incidence and pathology of polioencephalomalacia in weaned beef calves. Vet. Human Toxicol. 44:70-72.

Osweiler G.D., Carr T.F., Sanderson T.P., Carson T.L. \& Kinker J.A. 1995. Water deprivation-sodium ion toxicosis in cattle. J. Vet. Diagn. Invest. 7:583-585.

Owens F. 2007. Acidose clínica e subclínica. Anais 3ํㅗำósio de Nutrição de Ruminantes, Botucatu, SP, p.157-173. (Palestra)

Perez S.E., Vagnozzi A., Sur J.H., Odriozola E., Campero C.M. \& Odeon A.C. 2003. Retrospective analysis of cases with a diagnosis of cerebrocortical necrosis and its relation with type 5 bovine herpesvírus. Revta Argent. Microbiol. 35:69-73.

Pritchard D. \& Eggleston G.W. 1978. Nardoo fern and polioencephalomalacia. Aust. Vet. J. 54:204-205.

Putrino S.M., Leme P.R., Luz e Silva S., Manella M.Q., Nogueira Filho J.C.M. Lima C.G. \& Alleoni G.F. 2007. Digestibilidade aparente de dietas com níveis crescentes de concentrado em novilhos Brangus e Nelore. Arq. Bras. Med. Vet. Zootec. 59:406-413.

Radostits O.M., Gay C.C., Blood D.C. \& Hinchcliff K.W. 2007. Veterinary Medicine: A textbook of the diseases of cattle, horses, sheep, pigs, and goats. $10^{\text {th }}$ ed. W.B. Saunders, Philadelphia, p.724-725.
Raisbeck M.F. 1982. Is polioencephalomalacia associated with highsulfate diets? J. Am. Vet. Med. Assoc. 180:1303-1305.

Riet-Correa G., Duarte M.D., Barbosa J.D., Oliveira C.M.C., Cerqueira V.D., Brito M.F. \& Riet-Correa F. 2006. Meningoencefalite e polioencefalomalacia causada por Herpesvírus bovino-5 no Estado do Pará. Pesq. Vet. Bras. 26:44-46.

Rissi D.R., Oliveira F.N., Rech R.R., Pierezan F., Lemos R.A.A. \& Barros C.S.L. 2006. Epidemiologia, sinais clínicos e distribuição das lesões encefálicas em bovinos afetados por meningoencefalite por herpesvírus bovino-5. Pesq. Vet. Bras. 26:123-132.

Rissi D.R., Rech R.R., Flores E.F., Kommers G.D. \& Barros C.S. 2007. Meningoencefalite por herpesvírus bovino-5. Pesq. Vet. Bras. 27:251260.

Rissi D.R., Pierezan F., Sá e Silva M., Flores E.F. \& Barros C.S.L. 2008. Neurological disease in cattle in southern Brazil associated with Bovine herpevirus infection. J. Vet. Diagn. Invest. 20:346-349.

Sager R.L., Hamar D.W. \& Gould D.H. 1990. Clinical and biochemical alterations in calves with nutritionally induced polioencephalomalacia. Am. J. Vet. Res. 51:1969-1974.

Salvador S.W.C., Lemos R.A.A., Riet-Correa F., Roehe P.M. \& Osório A.L.A.R. 1998. Meningoencefalite em bovinos causada por herpesvírus bovino-5 no Mato Grosso do Sul e São Paulo. Pesq. Vet. Bras. 18:76-83

Sampaio I.B.M. 1998. Estatística Aplicada à Experimentação Animal. UFMG, Belo Horizonte. 221p.

Sanches A.W.D., Langohr I.M., Stigger A.L. \& Barros C.S.L. 2000. Doenças do sistema nervoso central em bovinos no Sul do Brasil. Pesq. Vet. Bras. 20:113-118

Sant'Ana F.J.F., Rissi D.R., Lucena R.B., Lemos R.AA, Nogueira A.P.A. \& Barros C.S.L. 2009a. Polioencefalomalacia em bovinos: epidemiologia, sinais clínicos e distribuição das lesões no encéfalo. Pesq. Vet. Bras. 29:487-497.

Sant'Ana F.J.F., Lemos R.AA, Nogueira A.P.A., Togni M., Tessele B. \& Barros C.S.L. 2009b. Polioencefalomalacia em ruminantes. Pesq. Vet. Bras. 29:681-694.

Sant'Ana F.J.F., Nogueira A.P.A., Souza R.I.C., Cardinal S.G., Lemos R.A.A. \& Barros C.S.L. 2009c. Polioencefalomalacia experimental induzida por amprólio em ovinos. Pesq. Vet. Bras. 29:747-752.

Santos M.N., Jardim Filho J.O. \& Grando F.A. 1983. Polioencefalomálacia em bovinos no Rio Grande do Sul. Pesq. Vet. Bras. 3:3739.

Sousa R.S. \& Irigoyen L.F. 1999. Intoxicação experimental por Phalaris angusta (Gramineae) em bovinos. Pesq. Vet. Bras. 19:116-122.

Stöber M. 1993. Sistema nervoso central, p.341-362. In: Dirksen G., Gründer H.D. \& Stöber M. (Eds), Exame Clínico dos Bovinos. Guanabara Koogan, Rio de Janeiro.

Traverso S.D., Colodel E.M., Loretti A.P., Seitz A.L., Correa A.M., Krauspenhar C. \& Driemeier D. 2001. Polioencefalomalacia em bovinos leiteiros no Rio Grande do Sul suplementados com enxofre. 10응 Enapave, Pirassununga, p.72. (Resumo)

Traverso S.D., Loretti A.P., Donini M.A. \& Driemeier D. 2004. Lead poisoning in cattle in southern Brazil. Arq. Bras. Med. Vet. Zootec. 56:418-421.

Trueman K.F. \& Clague D.C. 1978. Sodium chloride poisoning in cattle. Aust. Vet. J. 54:89-91.

Valadares Filho S.C., Pina D.S. \& Chizzotti M.L. 2006. Degradação ruminal da proteína dos alimentos e síntese de proteína microbiana, p.13-44. In: Valadares Filho S.C., Paulino P.V.R. \& Magalhães K.A. (Eds), Exigências Nutricionais de Zebuínos e Tabelas de Composição de Alimentos BR-Corte. Suprema Gráfica, Viçosa, MG. 142p. 